\title{
Article \\ Electrochemical Incorporation of Carbon Dioxide into Fluorotoluene Derivatives under Mild Conditions
}

\author{
Silvia Mena (D), Jesus Bernad and Gonzalo Guirado *(D)
}

Departament de Química, Universitat Autònoma de Barcelona, Campus UAB, 08193 Bellaterra, Barcelona, Spain; silvi_22-22@hotmail.com (S.M.); jesus.bernad1@gmail.com (J.B.)

* Correspondence: gonzalo.guirado@uab.cat; Tel.: +34-93-581-4882

\begin{abstract}
One of the main challenges to combat climate change is to eliminate or reuse Carbon dioxide $\left(\mathrm{CO}_{2}\right)$, the largest contributor to the greenhouse gases that cause global warming. It is also important to synthesize compounds through greener technologies in order to obtain more environmentally friendly solutions. This study describes the electrocarboxylation process of $\alpha, \alpha, \alpha-$ trifluorotoluene using different working electrodes (glassy carbon, silver and copper) and electrolytes (polar aprotic solvent and ionic liquid). Carboxylated compounds were obtained in the same way in both electrolytic medias with more than $80 \%$ conversion rates, high yields, good selectivity, and moderate efficiencies using silver and copper as cathodes in organic electrolytes and ionic liquids.
\end{abstract}

Keywords: ionic liquids; electrocarboxylation; $\mathrm{CO}_{2}$ valorization; $\alpha, \alpha, \alpha$-trifluorotoluene

Citation: Mena, S.; Bernad, J.;

Guirado, G. Electrochemical

Incorporation of Carbon Dioxide into Fluorotoluene Derivatives under Mild Conditions. Catalysts 2021, 11, 880. https://doi.org/10.3390/ catal11080880

Academic Editor: Francis Verpoort

Received: 25 June 2021

Accepted: 20 July 2021

Published: 22 July 2021

Publisher's Note: MDPI stays neutral with regard to jurisdictional claims in published maps and institutional affiliations.

Copyright: (c) 2021 by the authors. Licensee MDPI, Basel, Switzerland. This article is an open access article distributed under the terms and conditions of the Creative Commons Attribution (CC BY) license (https:// creativecommons.org/licenses/by/ $4.0 /)$.

\section{Introduction}

Atmospheric $\mathrm{CO}_{2}$ is the main source of carbon for life on Earth. However, even though carbon dioxide in the Earth's atmosphere is a trace gas compared to nitrogen $(78.1 \%)$ and oxygen (20.9\%), due to anthropogenic activity (fossil fuel combustion and deforestation) its atmospheric concentration has increased by about $43 \%$ since the beginning of industrialization [1]. Together with other anthropogenic gases, such as methane, $\mathrm{CO}_{2}$ is one of the greenhouse gases (GHG), and the largest contributor to global warming [2]. Renewable (or green) energy is a term that describes energy generated from environmentally friendly primary energy sources. Their production method does not emit by-products that can have a negative impact on the environment. Renewable energies include wind, hydroelectric, geothermal, tidal, solar, and biomass energies [3]. Carbon capture and storage (CCS) strategies involve several processes and materials used to sequester $\mathrm{CO}_{2}$ and store it underground long-term, e.g., in gas fields or reservoirs. Examples of strategies for $\mathrm{CO}_{2}$ capture and storage based on chemical systems are the use of aqueous amines, the most used of which are methanolamine (MEA) and diethanolamine (DEA), which are known to have a high affinity for $\mathrm{CO}_{2}$ [4]. Another common method is the use of MOFs [5] (with high potential but with less soft conditions), microalgae [6], bacteria, and ionic liquids [7].

$\mathrm{CO}_{2}$ is an abundant, low-cost, and non-flammable source of carbon, making it a $\mathrm{C} 1$ skeleton for building bigger molecules. Thanks to these properties, $\mathrm{CO}_{2}$ can act as a reagent, and is a very interesting component both for designing capture and utilization strategies (CCU) for obtaining chemical products and for its direct use as a solvent (supercritical $\mathrm{CO}_{2}$ ). Therefore, $\mathrm{CO}_{2}$ can be used in processes where it is converted into chemicals and fuels [8]. This can be achieved through carboxylation reactions in which the $\mathrm{CO}_{2}$ molecule is used as a precursor for organic compounds such as carbonates, acrylates, and polymers; or reduction reactions in which $\mathrm{C}=\mathrm{O}$ bonds are broken to produce chemical compounds such as methane, methanol, syngas, urea, and formic acid [4,9-11].

The electrochemical reduction of $\mathrm{CO}_{2}$, in both protic and aprotic solvents, begins with the formation of the radical anion $\mathrm{CO}_{2}{ }^{-}$. This radical anion is highly reactive and evolves in different ways depending on the working conditions. The main drawback 
associated with the direct electrochemical reduction of $\mathrm{CO}_{2}$ is that it occurs at very high reduction potentials. For example, $\mathrm{CO}_{2}$ is reduced beyond $-2.2 \mathrm{~V}$ vs. SCE in aprotic solvents [12]. For this reason, different catalytic pathways for reducing $\mathrm{CO}_{2}$ have been established, concluding that radical anions of aromatic esters and nitriles are very selective catalysts that can produce high yields of oxalate in the electrochemical reduction of $\mathrm{CO}_{2}$, lowering the potential in which it occurs $[12,13]$.

Another pathway in which $\mathrm{CO}_{2}$ can be electrochemically valorized within highly applied potentials is the electrocarboxylation process. This reaction consists in the utilization of $\mathrm{CO}_{2}$ as a reagent and carbon source for its incorporation in organic molecules, giving carboxylic acids or esters with one carbon elongation (Scheme 1). In this case, the reagent to be functionalized by incorporating $\mathrm{CO}_{2}$ is electrochemically activated instead of the gas. In general, this process is carried out at potentials that are less negative than $\mathrm{CO}_{2}$, allowing the in-situ generation of organic anions $\left(\mathrm{R}^{-}\right)$, which can potentially nucleophilically attack carbon dioxide leading to corresponding carboxylation processes.

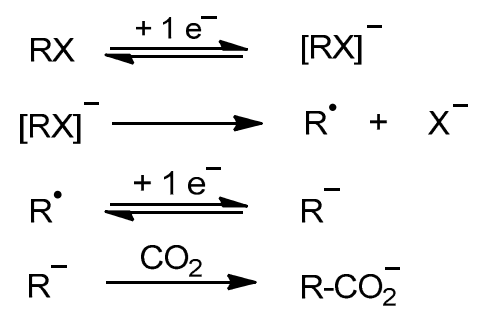

Scheme 1. Electrochemical carboxylation process.

There are different reports which described electrocarboxylation processed with a lot of different substrates $[14,15]$. One of the most studied and mature strategy to synthesize carboxylated compounds are the electrochemical carboxylations of organic halides, where Gennaro et al. showed that the use of silver as a working electrode improves the process because of the electrocatalytic properties of silver for C-halogen bond cleavage [16-19] or unsaturated compounds such as ketones [20], alcohols, or thioethers [21].

This pathway is an expanding track due to the associated working conditions (temperature and atmospheric pressure), which are more favorable and have a multitude of potential applications. However, the main disadvantage of performing electrochemical reactions is that protic or aprotic solvents are used, which are well-known hazardous substances, and supporting electrolytes are also used in high concentrations. Hence, an attractive alternative is the use of more sustainable solvents, such as ionic liquids. These are defined as fluids formed basically by ions, with low fusion points (less than $100{ }^{\circ} \mathrm{C}$ ), and that have unique properties, such as viscosity, density, solubility, and hydrophobicity, which can be modified in function of the needs required. Moreover, in the second generation of ionic liquids are the room temperature ionic liquids (RTILs), which are liquids at working conditions [22]. Hence, using electrochemistry and RTILs together is an alternative for creating greener electrochemical routes, substituting traditional organic solvents employed with other solvents that are safer and more environmentally friendly [23-25].

This alternative route for synthesizing carboxylic acids could be employed with trifluoromethylated compounds [26,27]. These are an important group in the fluoroalkyles group, and its carboxylic acid derivative has associated interest because it is a biologically active compound. In this regard, Savéant et al. [28] studied the reductive mechanism and reactivity of C-F bonds in trifluoromethylarenes, where the reduction leads to defluorinated products in a mechanism involving the formation of mono- and difluorinated species (Scheme 2). This reaction involves the elimination of a fluoride anion $\left(\mathrm{F}^{-}\right)$from a radical anion that is rapidly protonated. The difference between fluorine, bromine, and chlorine species is the greater strength of the carbon-fluorine bond. 


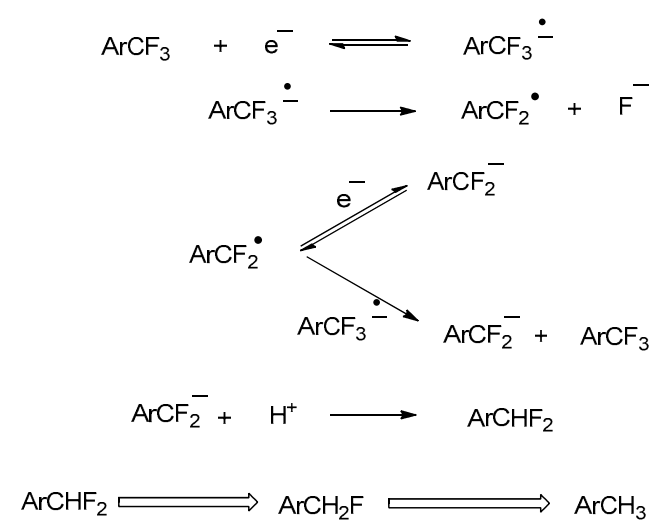

Scheme 2. Electrochemical reduction mechanism of trifluoromethylarene compounds proposed mechanism by Savéant et al. Reprinted with permission form reference [28]. Copyright (C) 1997, American Chemical Society.

The standard potential for the formation of the radical anion species increases from the mono- di- and trifluorinated species, so that the reduction of the three carbon-fluorine bonds requires six electrons. According to the reduction mechanism proposed above, the generation of different organic anions from the reduction and breaking of the C-F bond makes it possible to design a priori an electrocarboxylation product route based on the electrochemical activation of fluorinated reagents under mild conditions (Scheme 3).

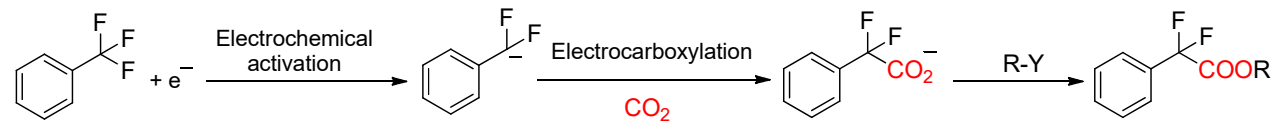

Scheme 3. Proposed route for the electrochemical valorization of $\mathrm{CO}_{2}$ through its electrochemical incorporation in $\alpha, \alpha, \alpha$-trifluorotoluene with an electrocarboxylation process.

Thus, an attractive alternative to conventional electrochemical solvents for carrying out these processes would be the use of ionic liquids. This strategy, which would synergistically combine electrochemistry, $\mathrm{CO}_{2}$ valorization, and green solvents, which has not been studies for this kind of reagents, would make it possible to obtain carboxylic acids from $\alpha, \alpha, \alpha$ trifluorotoluene, 1 (Figure 1).

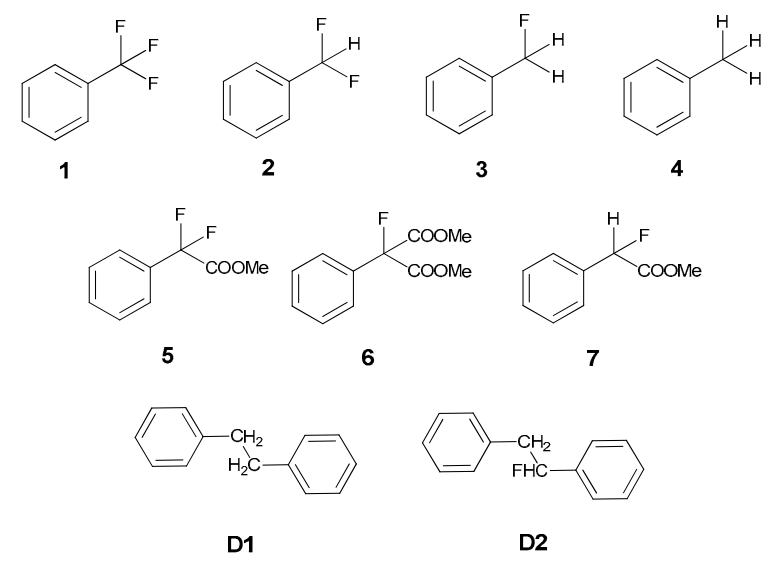

Figure 1. Chart of structures. Compound 1 is the reactant, whereas compounds 2-7 and D1-D2 are products obtained after controlled potential electrolysis under nitrogen or carbon dioxide atmosphere. 


\section{Results and Discussion}

The electrochemical behavior of $\alpha, \alpha, \alpha$-trifluorotoluene (1) was studied in different solvents and electrodes under an inert atmosphere in order to establish the optimal experimental conditions for the optimal electrochemical capture of $\mathrm{CO}_{2}$.

\subsection{Electrochemical Reduction of $\alpha, \alpha, \alpha$-trifluorotoluene under an Inert Atmosphere}

2.1.1. Electrochemical Reduction Mechanism of $\alpha, \alpha, \alpha$-trifluorotoluene in a Polar Aprotic Solvent

Cyclic voltammograms (CVs) were recorded at different scan rates (from 0.10 a $1.0 \mathrm{~V} \mathrm{~s}^{-1}$ ) using glassy carbon, GC (green line), silver, Ag (red line), and copper, $\mathrm{Cu}$ (black line) as working electrodes under a $\mathrm{N}_{2}$ atmosphere for a $10 \mathrm{~mL}$ solution of 1 in $N, N^{\prime}$-dimethylformamide (DMF) using $0.10 \mathrm{M}$ of tetrabutylammonium hexafluorophosphate $\left(\mathrm{TBA} \mathrm{PF}_{6}\right)$, Figure $2 \mathrm{a}$. The same general trend was observed in all cases. Several subsequent irreversible multi-electron waves ( $\sim 6$ electrons) are shown, whose electrochemical parameters are summarized in Table 1 . The use of silver and copper as a cathode seems to introduce a small electrocatalytic effect for the reduction processes performed in an aprotic organic electrolyte [29], due to the interaction between metal cathodes and reduction products obtained after electrochemical reduction and/or the intermediates.

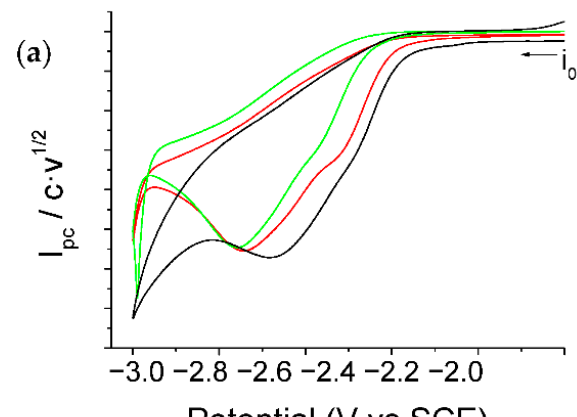

Potential (V vs SCE)

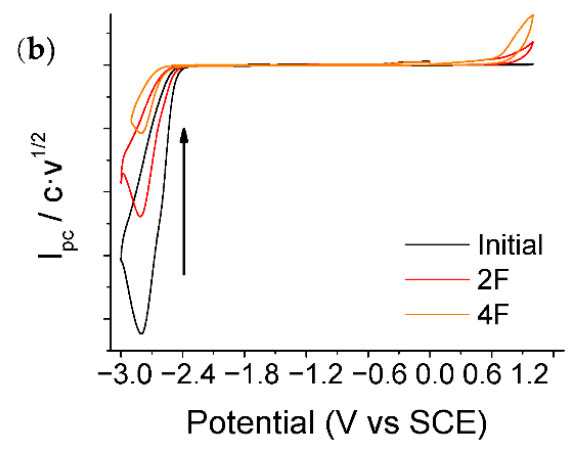

Figure 2. Cyclic voltammetry $(\mathrm{CV})$ of a 5-25 mM solution of 1 in DMF/0.1M TBA PF 6 . Scan rate: $0.3 \mathrm{~V} \cdot \mathrm{s}^{-1}$. Pt: counter electrode (CE), saturated calomel electrode (SCE): reference electrode (RE). working electrode (WE). (a) Glassy carbon (GC, green line), Ag (red line), Cu (black line). (b) Electrolysis monitorization through CV using with GC as a WE.

Table 1. Electrochemical parameters for a solution of 5.5-15 $\mathrm{mM}$ of $\mathbf{1}$ in DMF/0.1 M TBA PF 6 , for WE GC $(\mathrm{d}=1 \mathrm{~mm}), \mathrm{Ag}(\mathrm{d}=3 \mathrm{~mm})$ and $\mathrm{Cu}(\mathrm{d}=3 \mathrm{~mm})$.

\begin{tabular}{|c|c|c|c|c|}
\hline WE & $v(\mathrm{~V} / \mathrm{s})$ & $\mathrm{E}_{\mathrm{pc}}(\mathrm{V}$ vs. SCE) & $\Delta E_{p}(m V)^{a}$ & $\alpha$ \\
\hline \multirow{5}{*}{ GC } & 0.1 & -2.72 & 195 & 0.25 \\
\hline & 0.3 & -2.75 & 200 & 0.24 \\
\hline & 0.5 & -2.76 & 209 & 0.23 \\
\hline & 0.7 & -2.73 & 197 & 0.24 \\
\hline & 1.0 & -2.76 & 203 & 0.24 \\
\hline \multirow{5}{*}{$\mathrm{Ag}$} & 0.1 & -2.70 & 235 & 0.21 \\
\hline & 0.3 & -2.71 & 241 & 0.20 \\
\hline & 0.5 & -2.75 & 241 & 0.20 \\
\hline & 0.7 & -2.78 & 246 & 0.20 \\
\hline & 1.0 & -2.78 & 253 & 0.19 \\
\hline \multirow{5}{*}{$\mathrm{Cu}$} & 0.1 & -2.68 & 208 & 0.23 \\
\hline & 0.3 & -2.69 & 214 & 0.22 \\
\hline & 0.5 & -2.69 & 218 & 0.22 \\
\hline & 0.7 & -2.70 & 222 & 0.22 \\
\hline & 1.0 & -2.72 & 231 & 0.21 \\
\hline
\end{tabular}


A controlled potential electrolysis at a potential value of ca. $0.1 \mathrm{~V}$ more negative than the $\mathrm{E}_{\mathrm{pc}}$ (after the first reduction wave) was performed under an inert atmosphere using either carbon graphite (instead of glassy carbon), silver, or copper cathodes. The analysis of the sample after the electrolysis showed that the analogues of $\alpha, \alpha, \alpha$-trifluorotoluene, 2, 3, and 4 lose fluoride atoms and are hydrogenated: . Table 2 summarizes conversion rates obtained, which are determined by ${ }^{1} \mathrm{H}$ NMR and GC chromatography of the electrochemical crude reactions, and the Faraday efficiency of the process (reagent converted into product in function of the charge consumed). The yield of isolated products is ca. $5 \%$ less than the conversion rate values. This result is then compared to the observed quantity of product measured through another analytical method. It is possible to see that the use of $\mathrm{Ag}$ and $\mathrm{Cu}$ instead of carbon considerably increases the efficiency of the electrochemical reaction from $50 \%$ to $80 \%$. Besides, the electrochemical processes were monitored by cyclic voltammetry (Figure $2 b$ ).

Table 2. Product distribution after control potential electrolysis of 1 in DMF/0.1 M TBA PF 6 with carbon graphite, silver, and copper cathodes.

\begin{tabular}{|c|c|c|c|c|c|}
\hline Cathode & $\begin{array}{c}\text { E }_{\text {applied }} \\
\text { (V vs. SCE) }\end{array}$ & $\mathrm{C} \cdot \mathrm{mol}^{-1}$ & $\begin{array}{l}\text { Products } \\
\text { Obtained }\end{array}$ & $\begin{array}{c}\text { Conversion } \\
\text { Rates }^{a}\end{array}$ & Efficiency \\
\hline C & -2.9 & 4.7 & $\begin{array}{l}2 \\
3\end{array}$ & $\begin{array}{l}74 \\
26\end{array}$ & $50 \%$ \\
\hline $\mathrm{Ag}$ & -2.9 & 4.0 & $\begin{array}{l}2 \\
3 \\
4\end{array}$ & $\begin{array}{c}50 \\
50 \\
\text { Traces }\end{array}$ & $80 \%$ \\
\hline $\mathrm{Cu}$ & -2.9 & 3.7 & $\begin{array}{l}1 \\
2 \\
3\end{array}$ & $\begin{array}{c}\text { Traces } \\
52 \\
48\end{array}$ & $80 \%$ \\
\hline
\end{tabular}

a Abundance of specie i / Abundance of all species (through ${ }^{1} \mathrm{H}$ RMN and ${ }^{19} \mathrm{~F}$ RMN).

The electrochemical reduction mechanism of 1 in DMF/0.1M TBA $\mathrm{PF}_{6}$ under inert atmosphere was fully disclosed by the combined use of the electrochemical techniques mentioned above (cyclic voltammetry and controlled potential electrolysis experiments). Hence, it is possible to propose that $\mathbf{1}$ followed the electron transfer, chemical reaction, electron transfer (ECE) mechanism. Hence, in a first electrochemical step (E) the radical anion, 1, was generated. A first order chemical reaction (C) coupled to this first electron transfer led to the loss of fluoride anion and the obtention of a fluorobenzylic radical through a C-F bond cleavage reaction. Finally, the radical was reduced to an anion at the electrode surface $(\mathrm{E})$, which later protonated by reacting with the solvent or the supporting electrolyte cation (Scheme 4). This was repeated to obtain fluoromethylbenzene, 3, and toluene, 4 , as reported in the literature by Savéant and coworkers. [28] The chemical stability of the electrochemically generated a fluorobenzylic anion, which acts as a nucleophile leading, and opens the door to incorporating $\mathrm{CO}_{2}$ via the nucleophile-electrophile reaction through the electrochemical reduction of $\mathbf{1}$ under $\mathrm{CO}_{2}$ atmosphere.

\subsubsection{Electrochemical Reduction Mechanism of $\alpha, \alpha, \alpha$-trifluorotoluene in Ionic Liquid}

Once the electrochemical behavior of $\mathbf{1}$ had been analyzed in an electrolytic media based on organic electrolytes, it was changed to a greener electrolyte. The ionic liquid selected to perform the electrochemical study was BMPyr TFSI because of its hydrophobicity, which helps in the extraction and recycling process. Moreover, it has an associated broad electrochemical window in which it is possible to see the electrochemical processes. Figure 3 shows the cyclic voltammetry response of a solution of $\mathbf{1}$ in the IL with the three working electrodes in an inert atmosphere. Different subsequent reduction irreversible multi-electron waves ( $\sim 6$ electrons) are observed between the cathodic potentials $\mathrm{Epc}=-2.8 \mathrm{~V}$ and Epc $=-2.95 \mathrm{~V}$ (vs. SCE). Therefore, the same general electrochemical trend was observed when DMF was replaced by BMPyr TFSI under $\mathrm{N}_{2}$ atmosphere. 
E<smiles>FC(F)(F)c1ccccc1</smiles>

1<smiles>FC(F)(F)c1ccccc1</smiles>

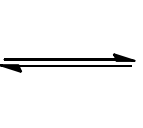

$\longrightarrow$<smiles>FC(F)(F)c1ccccc1</smiles><smiles>FC(F)c1ccccc1</smiles>

$E$<smiles>FC(F)c1ccccc1</smiles><smiles>FC(F)c1ccccc1</smiles><smiles>FC(F)c1ccccc1</smiles><smiles>FC(F)c1ccccc1</smiles>

Scheme 4. Proposed mechanism for the electrochemical reduction of $\alpha, \alpha, \alpha$-trifluorotoluene.

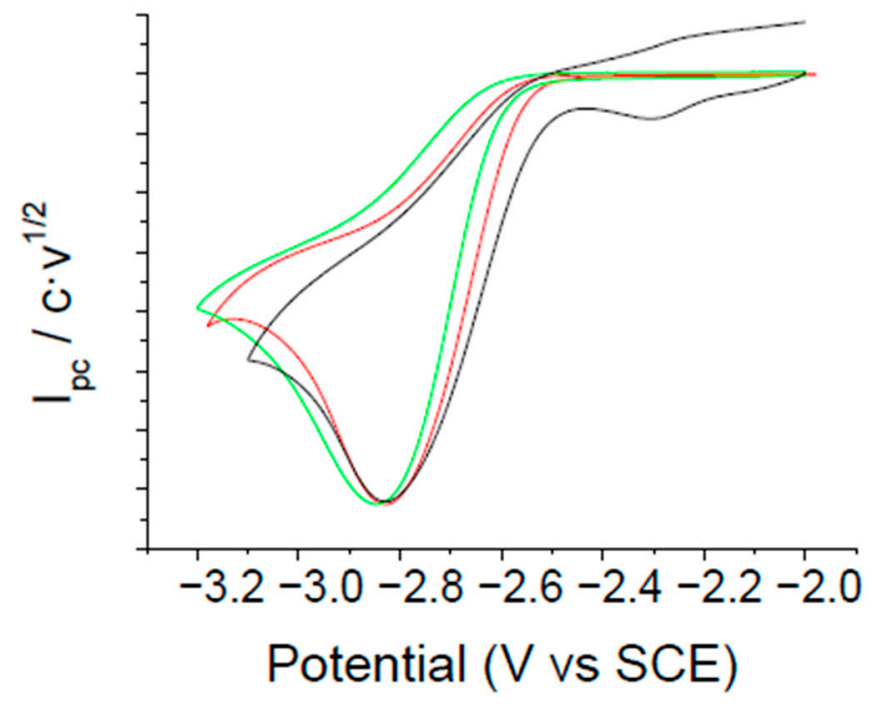

Figure 3. Cyclic voltammetry of $24 \mathrm{mM}$ of 1 in BMPyr TFSI with WE GC (green line), Ag (red line), $\mathrm{Cu}$ (black line), CE Pt and RE SCE. Scan rate: $0.3 \mathrm{~V} \cdot \mathrm{s}^{-1}$.

The electrochemical parameters for the electrochemical reduction of $\mathbf{1}$ are summarized in Table 3, which shows how the electron transfer is faster using the ionic liquid compared with the polar aprotic solvent ( $\alpha$ value ca. 0.4 vs. ca. 0.2 ). It seems the solvation of 1 , which is strongly related with the polarity of the electrolyte, favors the electron transfer process, being faster in IL than in DMF/0.1M TBA PF 6 . As a result, the ionic liquid can act as a (co)-catalyst making the electrochemical parameters, $\alpha$ and $\Delta \mathrm{E}_{\mathrm{p}}$, higher and lower in IL compared with organic electrolyte, respectively.

The number of electrons was obtained by functionalizing the intensity current and normalizing with a pattern of 9-fluorenone and titanocene (well-known cathodic redox probes) in the same experimental conditions.

With these data it is possible to propose the same ECE mechanism proposed above (Scheme 4) as the electrochemical mechanism for $\mathbf{1}$ in BMPyr TFSI, where compound $\mathbf{1}$ is reduced and loses its fluorine atoms in order to obtain products 2, 3, and 4. 
Table 3. Electrochemical parameters for a solution of $24 \mathrm{mM}$ of $\mathbf{1}$ in BMPyr TFSI, using as a working electrodes (WE): GC $(\mathrm{d}=1 \mathrm{~mm}), \mathrm{Ag}(\mathrm{d}=3 \mathrm{~mm})$ and $\mathrm{Cu}(\mathrm{d}=3 \mathrm{~mm})$.

\begin{tabular}{|c|c|c|c|c|c|}
\hline WE & $v(\mathrm{~V} / \mathrm{s})$ & $E_{p c}(V$ vs. SCE $)$ & $\Delta E_{p}(m V)^{a}$ & $\alpha$ & $\mathrm{n}^{\mathrm{o}}$ Electrons ${ }^{\mathrm{b}}$ \\
\hline \multirow{6}{*}{ GC } & 0.1 & -2.86 & 110 & 0.44 & $7.7_{4}$ \\
\hline & 0.3 & -2.87 & 109 & 0.44 & $6.5_{5}$ \\
\hline & 0.5 & -2.89 & 102 & 0.47 & $6.5_{3}$ \\
\hline & 0.7 & -2.91 & 120 & 0.40 & $6.1_{5}$ \\
\hline & 1 & -2.92 & 126 & 0.38 & $5.9_{5}$ \\
\hline & & & $113 \pm 9$ & 0.43 & $6.6 \pm 0.7$ \\
\hline \multirow{6}{*}{$\mathrm{Ag}$} & 0.1 & -2.86 & 99 & 0.49 & $7.6_{6}$ \\
\hline & 0.3 & -2.87 & 96 & 0.50 & $7.0_{3}$ \\
\hline & 0.5 & -2.88 & 99 & 0.49 & $6.3_{6}$ \\
\hline & 0.7 & -2.89 & 107 & 0.45 & $6.0_{2}$ \\
\hline & 1 & -2.90 & 113 & 0.43 & $5.8_{0}$ \\
\hline & & & $103 \pm 7$ & 0.47 & $6.6 \pm 0.8$ \\
\hline \multirow{6}{*}{$\mathrm{Cu}$} & 0.1 & -2.79 & 103 & 0.47 & $7.2_{4}$ \\
\hline & 0.3 & -2.80 & 102 & 0.47 & $7.0_{4}$ \\
\hline & 0.5 & -2.83 & 123 & 0.39 & $6.8_{3}$ \\
\hline & 0.7 & -2.83 & 124 & 0.39 & $6.0_{4}$ \\
\hline & 1 & -2.85 & 136 & 0.35 & $6.0_{8}$ \\
\hline & & & $\mathbf{1 1 8} \pm 14$ & 0.41 & $\mathbf{6 . 6} \pm 0.6$ \\
\hline
\end{tabular}

${ }^{a} \Delta E_{p}(m V)=\left(E_{p c}-E_{p 1 / 2}\right) \cdot 1000 .{ }^{b}$ The number of electrons was obtained by functionalizing the intensity current and normalizing with a pattern of 9-fluorenone and titanocene (well-known cathodic redox probes) in the same experimental conditions. The bold data is the average of the numbers in the column, which are above them.

\subsection{Electrochemical Study of $\alpha, \alpha, \alpha$-trifluorotoluene in a Saturated $\mathrm{CO}_{2}$ Atmosphere}

Before studying the electrochemical behavior of $\mathbf{1}$ in $\mathrm{CO}_{2}$ saturated solutions, it is necessary to perform an electrochemical study of $\mathrm{CO}_{2}$ with the three cathodic materials and in both electrolytes. For this reason, we prepared different $\mathrm{CO}_{2}$ solutions in DMF and IL. The concentration of $\mathrm{CO}_{2}$ in solution was determined using a thermal mass flowmeter, gravimetric methods, as well as by comparison with well-known redox probes such as 9-fluorenone and titanocene.

\subsection{1. $\mathrm{CO}_{2}$ Electrochemical Reduction Mechanism in DMF/0.1M TBA PF 6 and BMPyr TFSI}

Figure 4 shows the $\mathrm{CO}_{2}$ cyclic voltammetry in both electrolytic medias using three working electrodes. Using a carbon working electrode, it is not possible to see an electrochemical response of $\mathrm{CO}_{2}$ reduction, only a slight rise in the intensity current (Figure $4 a, b$ ). On the contrary, when using silver (Figure $4 \mathrm{c}, \mathrm{d}$ ) and copper (Figure $4 \mathrm{e}, \mathrm{f}$ ) as working electrodes there is a new peak related to the direct reduction of $\mathrm{CO}_{2}$ on their surface.

Table 4 summarizes the electrochemical parameters of the electron transfer obtained in both electrolytic medias, showing a slow irreversible electron transfer in both cases. It is important to highlight how that the nature of the cathode as well as the electrolyte shifted the reduction peak potential values, making the process energetically more favorable. The combined use of silver and copper cathodes and ILs, as catalyst and cocatalyst, allows to make lower the potential in which $\mathrm{CO}_{2}$ is reduced [23-25]. Note that the $\mathrm{CO}_{2}$ cathodic peak potential diminishes in $138 \mathrm{mV}$ (with $\mathrm{Cu}$ ) and $588 \mathrm{mV}$ (with $\mathrm{Ag}$ ) when the organic electrolyte (DMF/0.1M TBA $\mathrm{PF}_{6}$ ) is replaced by the ionic liquid (BMPyr TFSI). This can be explained by considering that the IL is a pure ion solvent, which means that the concentration of the counter-cation is considerably higher in IL than in DMF solution where "only" a $0.1 \mathrm{M}$ concentration of tetrabutylammonium cation is present, so the formed product $\left(\mathbf{1}^{-}\right)$ would be strongly solvated in IL being the reduction potential value of the process less negative. 
WE GC

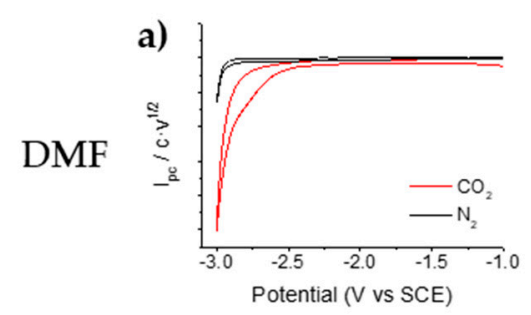

IL

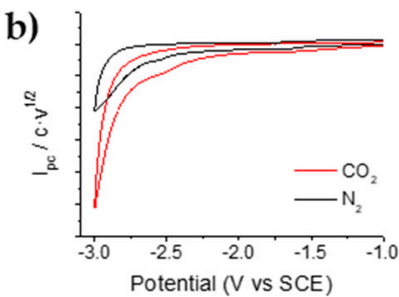

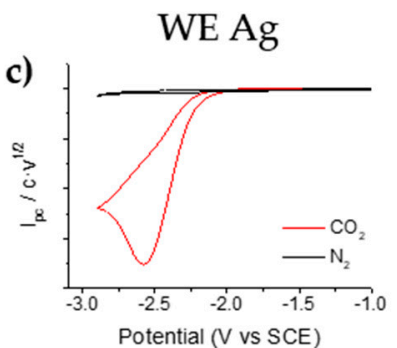

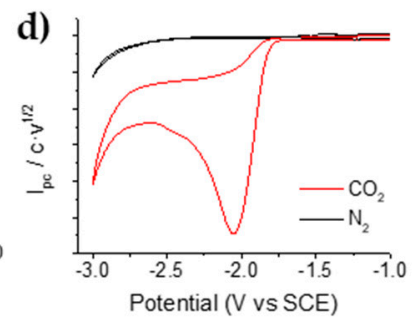

WE Cu
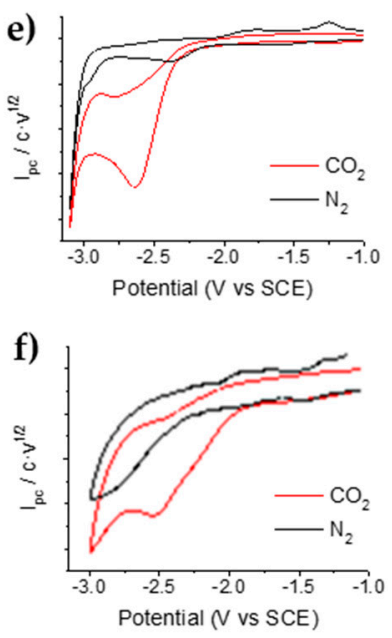

Figure 4. Cyclic voltammetry of $\mathrm{CO}_{2}$ saturated solutions of DMF/0.1 M TBA PF 6 with WE: (a) GC (c) WE Ag and (e) WE Cu. Cyclic voltammograms of $\mathrm{CO}_{2}$ saturated solutions of BMPyr TFSI with WE: (b) GC (d) Ag (f) Cu. Scan rate: $0.5 \mathrm{~V} \cdot \mathrm{s}^{-1}$.

Table 4. Electrochemical parameters for solutions of $\mathrm{CO}_{2}$ in both electrolytic medias, with the use of GC, Ag, and Cu cathodes).

\begin{tabular}{|c|c|c|c|c|}
\hline Cathode & $E_{p c}(V)$ vs. SCE & $\Delta E_{p}(m V)^{a}$ & $\alpha^{b}$ & {$\left[\mathrm{CO}_{2}\right](\mathrm{mM})$} \\
\hline \multicolumn{5}{|c|}{ DMF/0.1M TBA PF $_{6}$} \\
\hline GC & - & - & - & - \\
\hline $\mathrm{Ag}$ & -2.638 & 244 & 0.20 & 118 \\
\hline $\mathrm{Cu}$ & -2.676 & 192 & 0.25 & 118 \\
\hline \multicolumn{5}{|c|}{ BuMePyr TFSI } \\
\hline GC & - & - & - & - \\
\hline $\mathrm{Ag}$ & -2.050 & 144 & 0.33 & 454 \\
\hline $\mathrm{Cu}$ & -2.538 & 375 & 0.13 & 454 \\
\hline
\end{tabular}

${ }^{\mathrm{a}} \Delta \mathrm{E}_{\mathrm{p}}(\mathrm{mV})=\left(\mathrm{E}_{\mathrm{pc}}-\mathrm{E}_{\mathrm{p} 1 / 2}\right) \cdot{ }^{\mathrm{b}} \Delta \mathrm{E}_{\mathrm{p}}(\mathrm{mV})=47.7 / \alpha$.

2.2.2. Electrocarboxylation of $\alpha, \alpha, \alpha$-trifluorotoluene in $\mathrm{DMF} / 0.1 \mathrm{M} \mathrm{TBA} \mathrm{PF}_{6}$ and BMPyr TFSI

After electrochemically characterizing $\mathrm{CO}_{2}$ in both electrolytic medias with three working electrodes, a cyclic voltammetry study of 1 was performed in a saturated $\mathrm{CO}_{2}$ atmosphere. Figure 5 shows how new electron waves appear depending on the working material employed. Using a carbon working electrode, the same behavior as in the inert atmosphere is observed: only an irreversible, slow multielectron wave, with a slight rise in the current intensity (Figure 5a,b). However, when silver or copper are used as working electrodes, new reduction peaks appear at $\mathrm{E}_{\mathrm{pc}} \sim-2.6 \mathrm{~V}$ (vs. SCE) in DMF/0.1 M TBA PF 6 , which overlaps the wave related to the compound 1 reduction (Figure $5 c, e$ ). In the case of the BMPyr TFSI ionic liquid, a new peak appears at $\mathrm{E}_{\mathrm{pc}} \sim-2.0 \mathrm{~V}$ (vs. SCE) with silver (Figure 5d) as was reported in [30] and at $\mathrm{E}_{\mathrm{pc}} \sim-2.5 \mathrm{~V}$ (vs. SCE) with copper (Figure 5f), which overlaps with the wave related to compound 1 reduction.

These new peaks correspond with $\mathrm{CO}_{2}$ reduction on the surface of $\mathrm{Ag}$ and $\mathrm{Cu}$, as was observed above, since both electrodes catalyze the direct reduction of $\mathrm{CO}_{2}$ on their surface. On the other hand, compound 1 has the same electrochemical behavior as in inert atmosphere, so it is possible to perform the electrocarboxylation reactions through the anions obtained in the ECE mechanism proposed for $\alpha, \alpha, \alpha$-trifluorotoluene. 
WE GC

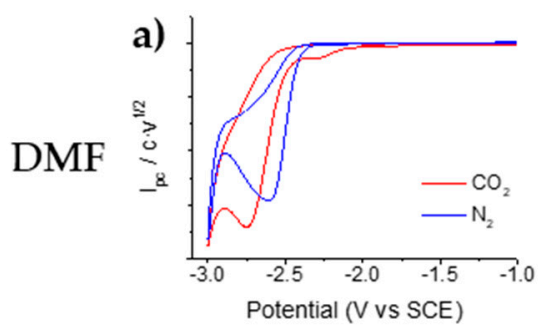

b)

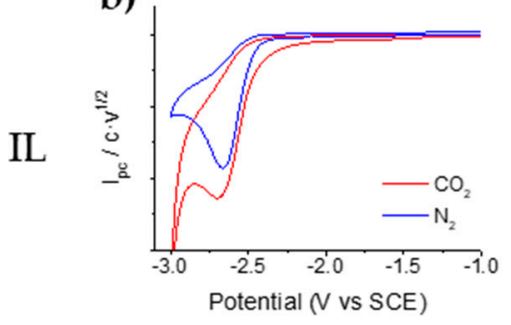

WE Ag

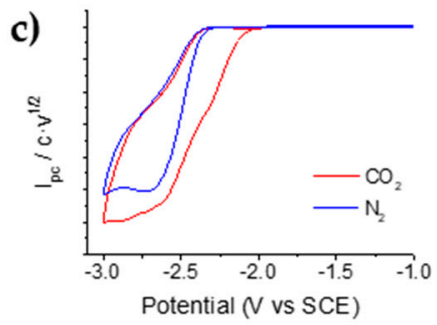

d)

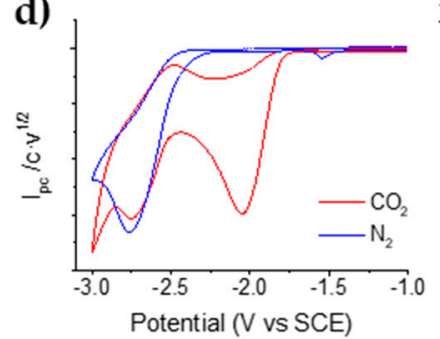

WE Cu
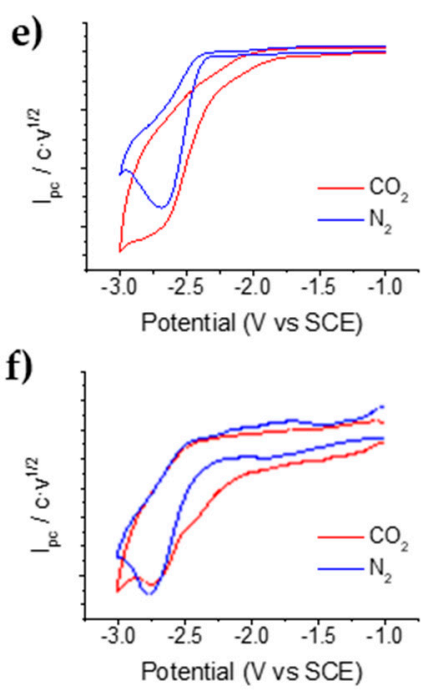

Figure 5. Cyclic voltammetry of solutions of $10-25 \mathrm{mM}$ of 1 and $0.1-0.4 \mathrm{M}\left[\mathrm{CO}_{2}\right]$ in DMF/0.1M TBA PF 6 using as WE (a) GC, (c) Ag and (e) Cu. Cyclic voltammograms in BMPyr TFSI with WE (b) GC, (d) Ag and (f) Cu. Scan rate: $0.5 \mathrm{~V} \cdot \mathrm{s}^{-1}$.

So, exhaustive control potential electrolysis $(0.1 \mathrm{~V}$ more negative than the potential of the cathodic peak) was performed with solution $1 \mathrm{in} \mathrm{DMF} / 0.1 \mathrm{M} \mathrm{TBA} \mathrm{PF}_{6}$ and $\mathrm{BMPyr}$ TFSI ionic liquid, using silver and copper because higher yields were obtained in an inert atmosphere. Next, the electrolysis methyl iodide $\left(\mathrm{CH}_{3} \mathrm{I}\right)$ was added to improve the extraction process and obtain the carboxylated compounds. The electrocarboxylation processes and products obtained are summarized in Table 5.

Table 5. Products obtained after the electrochemical carboxylation of $\mathbf{1}$ in both electrolytic medias with three different cathode materials.

\begin{tabular}{|c|c|c|c|c|c|}
\hline \multicolumn{6}{|c|}{ DMF/0.1M TBA PF $_{6}$} \\
\hline Cathode & $\begin{array}{l}\text { E }_{\text {applied }} \\
\text { (V) }\end{array}$ & $\mathrm{C} \cdot \mathrm{mol}^{-1}$ & $\begin{array}{c}\text { Defluorinated } \\
\text { Products } \\
\text { (Yield\%) }^{a}\end{array}$ & $\begin{array}{c}\text { Carboxylated } \\
\text { Products } \\
\left(\text { Yield \%) }^{a}\right.\end{array}$ & $\begin{array}{c}\text { Efficiency } \\
\text { Electrocarboxylation }\end{array}$ \\
\hline $\mathrm{Ag}$ & -2.8 & 6.2 & $\begin{array}{l}\text { D1 }(6 \%) \\
\text { D2 }(5 \%)\end{array}$ & $\begin{array}{l}5(82 \%) \\
7(7 \%)\end{array}$ & $31 \%$ \\
\hline $\mathrm{Cu}$ & -2.8 & 4.2 & $3(26 \%)$ & $\begin{array}{c}5(70 \%) \\
6(4 \%)\end{array}$ & $37 \%$ \\
\hline \multicolumn{6}{|c|}{ BuMePyr TFSI } \\
\hline Cathode & $\begin{array}{l}\text { Eapplied } \\
\text { (V) }\end{array}$ & $\mathrm{C} \cdot \mathrm{mol}^{-1}$ & $\begin{array}{l}\text { Carboxylated } \\
\text { Products }\end{array}$ & Yield $^{\text {a }}$ & $\begin{array}{c}\text { Efficiency } \\
\text { Electrocarboxylation }\end{array}$ \\
\hline $\mathrm{Ag}$ & -2.9 & 6.0 & 5 & $100 \%$ & $33 \%$ \\
\hline $\mathrm{Cu}$ & -2.9 & 6.0 & $\begin{array}{l}5 \\
7\end{array}$ & $\begin{array}{l}31 \% \\
69 \%\end{array}$ & $56 \%$ \\
\hline
\end{tabular}

${ }^{a}$ Abundance if species i/Abundance of all species (through CG/MS).

In solutions of DMF, the main product is $\mathbf{5}$ with both working electrodes, obtaining yields ca. $74-89 \%$ and efficiencies ca. $31-37 \%$ for the electrocarboxylation process. However, although after the first C-F cleavage the majority of the product of the electrocarboxylation process is obtained, the obtention of D1 and D2 (in the case of Ag), and 3 in the case of $\mathrm{Cu}$, indicates that the electrocarboxylation process competes either with the hydrogenation and dimerization processes in $\mathrm{Cu}$ and $\mathrm{Ag}$, respectively. The use of ionic liquids, BMPyr TFSI, as electrolyte favors the electrocarboxylation reaction being quantitative to the elec- 
trocarboxylation reaction when $\mathrm{Ag}$ or $\mathrm{Cu}$ are used as cathodes. This fact can be explained by taking in to account the greater stability of the fluorobenzylic anion as well as the higher concentration of $\mathrm{CO}_{2}$ under $\mathrm{CO}_{2}$ saturated atmosphere in the IL $[25,30]$. Finally, it is important to highlight that the use of $\mathrm{Cu}$ as a cathode increases the efficiency of the electrocarboxylation reaction, whereas the use of silver makes it totally selective.

Finally, with the combined use of the data obtained after cyclic voltammetry and control potential electrolysis, an ECE mechanism could be proposed followed by an electrocarboxylation process as a synthetic route for obtaining carboxylated fluorinated compounds through, $\alpha, \alpha, \alpha$-trifluorotoluene in both organic and BMPyr TFSI electrolytes (Scheme 5).

$\mathrm{E}$

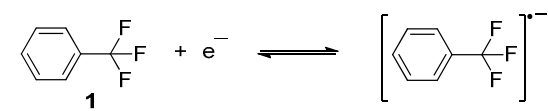

c

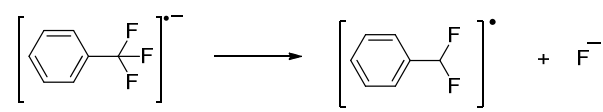

E
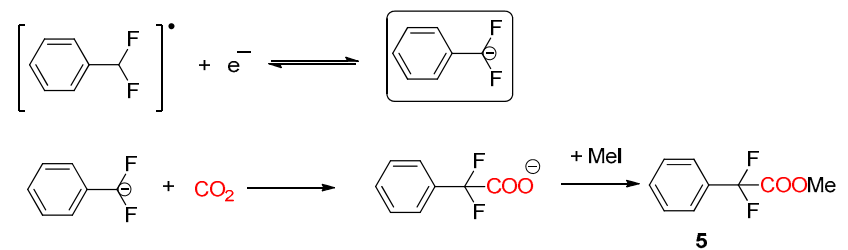

$\mathrm{E}$

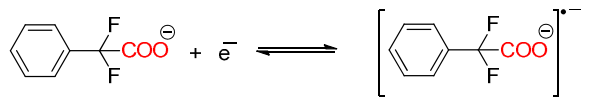

c

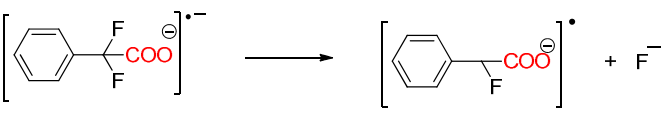

E

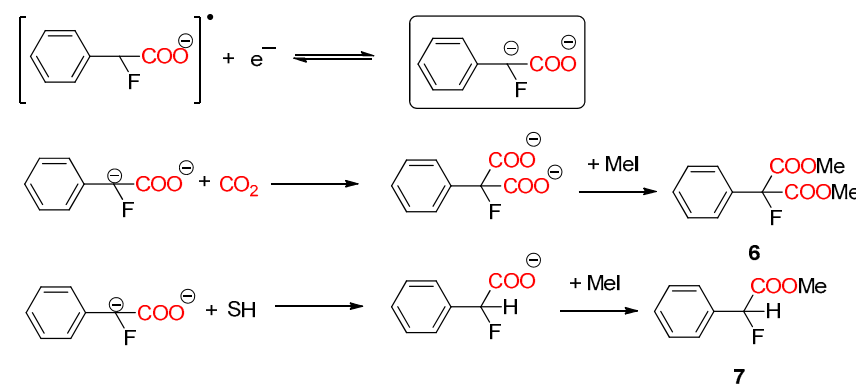

Scheme 5. Proposed mechanism for the electrochemical activation of $\alpha, \alpha, \alpha$-trifluorotoluene followed by electrochemical carboxylation.

\section{Materials and Methods}

\subsection{Materials}

Carbon dioxide $\left(\mathrm{CO}_{2}\right)$ and nitrogen $\left(\mathrm{N}_{2}\right)$ gases were purchased from Carburos Metálicos S.A. (Cornellà de Llobregat, Barcelona, Spain), with a purity of 99.9999\%. All of the commercially available reagents, $\alpha, \alpha, \alpha$-trifluorotoluene, iodomethane (MeI), $\mathrm{N} \mathrm{N}^{\prime}$-dimethylformamide $(\mathrm{DMF})$, and tetrabutylammonium hexafluorophosphate $\left(\mathrm{TBA} \mathrm{PF}_{6}\right)$ were acquired from Sigma-Aldrich (Madrid, Spain) with maximum purity and used as received. 1-butyl-1methylpyrrolidinium bis(trifluoromethylsulphonyl)imide (BMPyr TFSI) was acquired from Solvionic (Toulouse, France) and was dried with activated molecular sieves for $24 \mathrm{~h}$ to guarantee that the amount of water was always less than $100 \mathrm{ppm}$.

\subsection{Electrochemical Experiments}

A three-electrode electrochemical system in a one-compartment conical cell was used for the set-up of cyclic voltammetry (CV) and controlled potential electrolysis. The electrochemical details of those techniques have been previously described [13,19,21-25]. 
When either organic electrolytes and ionic liquids are used, the current values obtained were first normalized by the concentration and the scan rate $\left(\mathrm{Ip} / \mathrm{cv}^{1 / 2}\right)$ aiming the direct comparison between the cyclic voltammograms in the different cathodes (glassy carbon, silver and copper). For the electrolysis experiments, the disc working electrodes were replaced by a graphite carbon bar and silver or copper foils. Compounds were electrolyzed at a negative potential of $0.10 \mathrm{~V}$ more negative than the $\mathrm{E}_{\mathrm{pc}}$ potential value under nitrogenor carbon dioxide-saturated solutions. When the reaction was completed, a methylation agent, methyl iodide $\left(\mathrm{MeI}\right.$ or $\left.\mathrm{CH}_{3} \mathrm{I}\right)$, was added to improve the extraction process and obtain the carboxylated compounds. The mixture was extracted in two different ways depending on the electrolyte media: when it is performed in DMF solutions, the mixture was extracted with water/ether mixtures (2:1). The organic layer was dried with $\mathrm{Na}_{2} \mathrm{SO}_{4}$ and evaporated to yield a residue. However, when IL is employed, the products of the electrolyzed solution were extracted with ether, making it possible to recover almost $80 \%$ of the ILs at the end of the process, after purification [25]. The organic layer was lastly washed with water and dried with $\mathrm{Na}_{2} \mathrm{SO}_{4}$ and evaporated to yield a residue. In some cases, the products were isolated using column chromatography. All residues or products obtained were dissolved in deuterated chloroform $\mathrm{CDCl}_{3}$ and characterized by proton nuclear magnetic resonance $\left({ }^{1} \mathrm{H}-\mathrm{NMR}\right)$, gas chromatography (GC), and gas chromatography-mass spectroscopy (GC-MS) and compared with their respective pure commercially-available analogues.

${ }^{1} \mathrm{H}-\mathrm{NMR}$ and ${ }^{19} \mathrm{~F}-\mathrm{NMR}$ measurements were performed in a Bruker DPX250 (250 MHz) with a Quattro Nucleus Probe (QNP) (Billerica, MA, USA). Proton Chemical shifts were reported in ppm $(\delta)\left(\mathrm{CDCl}_{3}, \delta=7.26\right)$. The $\mathrm{J}$ values are reported in $\mathrm{Hz}$. Fluor Chemical shifts were reported in ppm $(\delta)\left(\mathrm{CDCl}_{3}\right)$. GC-MS analysis were performed using an Agilent Technologies 6850 GC instrument with a 5975C detector Hewlett Packard (Santa Clara, CA, USA).

$\mathrm{PhCF}_{3}(\mathbf{1}):{ }^{1} \mathrm{H} \mathrm{RMN}\left(\mathrm{CDCl}_{3}\right) \delta(\mathrm{ppm}): 7.75-7.30(\mathrm{~m}, 5 \mathrm{H}) .{ }^{19} \mathrm{~F} \mathrm{RMN}\left(\mathrm{CDCl}_{3}\right) \delta(\mathrm{ppm}):$ $-63.3(\mathrm{~s}, 3 \mathrm{~F})$.

$\mathrm{PhCF}_{2} \mathrm{H}(2):{ }^{1} \mathrm{H} \mathrm{RMN}\left(\mathrm{CDCl}_{3}\right) \delta(\mathrm{ppm}): 7.48-7.30(\mathrm{~m}, 5 \mathrm{H}) ; 6.64(\mathrm{t}, \mathrm{J}=56,5 \mathrm{~Hz}, 1 \mathrm{H}) .{ }^{19} \mathrm{~F}$ $\mathrm{RMN}\left(\mathrm{CDCl}_{3}\right) \delta(\mathrm{ppm}):-111.1(\mathrm{~s}, 2 \mathrm{~F})$.

$\mathrm{PhCFH}_{2}$ (3): 1H RMN (CDCl $) \delta$ (ppm): 7.55-7.25 (m, 5H) $5.37(\mathrm{~d}, \mathrm{~J}=47.8 \mathrm{~Hz}, 2 \mathrm{H})$.

$\mathrm{PhCH}_{3}$ (4): GC-MS (70 eV): $m / z$ (\%): 92.0 (78) [M+]; $91.0(100)\left[\mathrm{M}^{+}-\mathrm{H}\right] ; 65.0$ (12) $\left[\mathrm{M}^{+}\right.$

$\left.-\mathrm{C}_{2} \mathrm{H}_{3}\right] ; 39.0$ (11). ${ }^{1} \mathrm{H}$ RMN $\left(\mathrm{CDCl}_{3}\right) \delta$ (ppm): $7.33-7.10(\mathrm{~m}, 5 \mathrm{H}) ; 2.34(\mathrm{~s}, 3 \mathrm{H})$.

$\mathrm{PhCF}_{2} \mathrm{COOMe}(5): \mathrm{GC}-\mathrm{MS}(70 \mathrm{eV}): \mathrm{m} / z$ (\%): $186.0(9)\left[\mathrm{M}^{+}\right] ; 127.0(100)\left[\mathrm{M}^{+}-\mathrm{C}_{2} \mathrm{H}_{3} \mathrm{O}_{2}\right] ;$ 77.0 (10) $\left[\mathrm{M}^{+}-\mathrm{C}_{3} \mathrm{H}_{3} \mathrm{O}_{2} \mathrm{~F}_{2}\right] ; 59.0(4)\left[\mathrm{M}^{+}-\mathrm{C}_{7} \mathrm{H}_{5} \mathrm{~F}_{2}\right] .{ }^{1} \mathrm{H} \mathrm{RMN}\left(\mathrm{CDCl}_{3}\right) \delta$ (ppm): 7.65-7.40 $(\mathrm{m}, 5 \mathrm{H}) ; 3.87(\mathrm{~s}, 3 \mathrm{H}) .{ }^{19} \mathrm{~F} \mathrm{RMN}\left(\mathrm{CDCl}_{3}\right) \delta(\mathrm{ppm}):-104.2(\mathrm{~s}, 2 \mathrm{~F})$.

$\mathrm{PhCF}(\mathrm{COOMe})_{2}(6):{ }^{1} \mathrm{H} \mathrm{RMN}\left(\mathrm{CDCl}_{3}\right) \delta(\mathrm{ppm}): 7.45-7.25(\mathrm{~m}, 5 \mathrm{H}) ; 3,80(\mathrm{~s}, 6 \mathrm{H}) .{ }^{19} \mathrm{~F}$ $\mathrm{RMN}\left(\mathrm{CDCl}_{3}\right) \delta(\mathrm{ppm}):-152.5(\mathrm{~s}, 1 \mathrm{~F})$.

PhCHFCOOMe (7): GC-MS (70 eV): $m / z(\%): 168.0(25)\left[\mathrm{M}^{+}\right] ; 109.0(100)\left[\mathrm{M}^{+}-\right.$ $\left.\mathrm{C}_{2} \mathrm{H}_{3} \mathrm{O}_{2}\right] ; 89.0$ (5) $\left[\mathrm{M}^{+-} \mathrm{C}_{2} \mathrm{H}_{4} \mathrm{O}_{2} \mathrm{~F}\right] ; 83.0$ (11); 77.0 (3) $\left[\mathrm{M}^{+}-\mathrm{C}_{3} \mathrm{H}_{4} \mathrm{O}_{2} \mathrm{~F}\right] ; 59.0$ (7) $\left[\mathrm{M}^{+}-\right.$ C7H6F]. ${ }^{1} \mathrm{H} \mathrm{RMN}\left(\mathrm{CDCl}_{3}\right) \delta(\mathrm{ppm}): 7.65-7.40(\mathrm{~m}, 5 \mathrm{H}) ; 5.82(\mathrm{~d}, \mathrm{~J}=47.9 \mathrm{~Hz}, 1 \mathrm{H}) ; 3.87$ (s, $3 \mathrm{H}) .{ }^{19} \mathrm{~F} \mathrm{RMN}\left(\mathrm{CDCl}_{3}\right) \delta(\mathrm{ppm}):-180.2(\mathrm{~d}, 1 \mathrm{~F})$.

$\mathrm{PhCH}_{2} \mathrm{CH}_{2} \mathrm{Ph}$ (D1): GC-MS (70 eV): $m / z$ (\%): 182.1 (25) $\left[\mathrm{M}^{+}\right] ; 146.0$ (17); 117.0 (8);

104.0 (8); $91.0(100)\left[\mathrm{M}^{+}-\mathrm{C}_{7} \mathrm{H}_{7}\right] ; 73.0(9) ; 65.0(14) ; 43.0$ (14).

$\mathrm{PhCHFCH}_{2} \mathrm{Ph}$ (D2): (70 eV): $m / z$ (\%): 200.1 (60) [M+ $] 172.1$ (17); 117.0 (20); 109.0 (100) $\left[\mathrm{M}^{+}-\mathrm{C}_{7} \mathrm{H}_{7}\right] ; 91.0$ (66) $\left[\mathrm{M}^{+}-\mathrm{C}_{7} \mathrm{H}_{6} \mathrm{~F}\right] ; 82.0$ (75); 65.0 (16); 54.0 (17); 41.0 (16).

\subsection{Determination of the $\mathrm{CO}_{2}$ Concentration in Solution}

A thermal mass flow meter (EL-FLOW ${ }^{\circledR}$ Mass Flow Meter/Controller, (Bronkhorst $\mathrm{Hi}-\mathrm{Tec}$, Ruurlo, Netherlands) was used to control $\mathrm{CO}_{2}$ concentrations in the solution. Secondary methods have been also used for verifying the $\mathrm{CO}_{2}$ concentration values. Hence, Titanocene $\left(\mathrm{E}^{0}=-1.07 \mathrm{~V}\right.$ vs. $\left.\mathrm{SCE}\right)$ was used as a one-electron redox probe in organic electrolytes, whereas a gravimetric methodology was used as also used for validating $\mathrm{CO}_{2}$ concentrations in ionic liquids. 


\section{Conclusions}

This manuscript describes a new "environmentally-friendly" electrochemical approach for producing highly valuable compounds using $\mathrm{CO}_{2}$ as a building block in ILs through the electrochemical carboxylation of trifluoromethyl aromatic derivatives. The electrochemical reduction mechanism of $\alpha, \alpha, \alpha$-trifluorotoluene (ECE) was determined with three different working electrodes: carbon, silver, and copper; and in two different electrolyte media: DMF/0.1M TBA $\mathrm{PF}_{6}$ and BMPyr TFSI ionic liquid. It was shown that the obtention of an anionic aromatic species after C-F cleavage could be used as a nucleophile in an electrochemical carboxylation process. Therefore, $\mathrm{CO}_{2}$ was characterized prior in both electrolytes with all the above-mentioned cathodic materials through cyclic voltammetry. Next, a "green electrochemical" was design in organic electrolytes and ILs. $\alpha, \alpha, \alpha$-Trifluorotoluene $\left(\mathrm{PhCF}_{3}\right)$ was carboxylated through a control potential electrolysis in saturated $\mathrm{CO}_{2}$ solutions. We obtained quantitative electrocarboxylation yields and good efficiencies when $\mathrm{Cu}$ or Ag cathodes were employed in ILs. Finally, the use of Ag and ILs allow to design a fully quantitative and selective electrochemical carboxylation reaction for obtaining $\mathrm{PhCF}_{2} \mathrm{COOMe}$ from $\mathrm{PhCF}_{3} \mathrm{COOMe}$ in mild conditions.

Author Contributions: G.G. conceived and designed the experiments; S.M. and J.B. performed the experiments and analyzed the data. S.M. and G.G. wrote the paper. Funding Acquisition, G.G. All authors have read and agreed to the published version of the manuscript.

Funding: This research was funded by MINECO/FEDER (project CTQ2015-65439-R) and Ministerio de Ciencia e Innovación (PID2019-106171RB-I00) of Spain.

Acknowledgments: The authors thank the Ministerio de Ciencia e Innovación of Spain for financial support though the project CTQ 2015-65439-R and PID2019-106171RB-I00. S.M. is grateful to the Universitat Autònoma de Barcelona for pre-doctoral PIF fellowships.

Conflicts of Interest: The authors declare no conflict of interest.

\section{References}

1. Bekun, F.V.; Alola, A.A.; Sarkodie, S.A. Toward a sustainable environment: Nexus between $\mathrm{CO}_{2}$ emissions, resource rent, renewable and nonrenewable energy in 16-EU countries. Sci. Total Environ. 2019, 657, 1023-1029. [CrossRef]

2. Şen, Z. Global warming threat on water resources and environment: A review. Environ. Earth Sci. 2009, 57, 321-329. [CrossRef]

3. Gielen, D.; Boshell, F.; Saygin, D.; Bazilian, M.D.; Wagner, N.; Gorini, R. The role of renewable energy in the global energy transformation. Energy Strategy Rev. 2019, 24, 38-50. [CrossRef]

4. Godin, J.; Liu, W.; Ren, S.; Xu, C.C. Advances in recovery and utilization of carbon dioxide: A brief review. J. Environ. Chem. Eng. 2021, 9, 105644. [CrossRef]

5. Ikreedeegh, R.R.; Tahir, M. A critical review in recent developments of metal-organic-frameworks (MOFs) with band engineering alteration for photocatalytic $\mathrm{CO}_{2}$ reduction to solar fuels. J. $\mathrm{CO}_{2}$ Util. 2021, 43, 101381. [CrossRef]

6. Babin, A.; Vaneeckhaute, C.; Iliuta, M.C. Potential and challenges of bioenergy with carbon capture and storage as a carbonnegative energy source: A review. Biomass Bioenergy 2021, 146, 105968. [CrossRef]

7. Bara, J.E.; Camper, D.E.; Gin, D.; Noble, R.D. Room-Temperature Ionic Liquids and Composite Materials: Platform Technologies for CO2 Capture. Acc. Chem. Res. 2010, 43, 152-159. [CrossRef]

8. Atsbha, T.A.; Yoon, T.; Seongho, P.; Lee, C.-J. A review on the catalytic conversion of $\mathrm{CO}_{2}$ using $\mathrm{H}_{2}$ for synthesis of CO, methanol, and hydrocarbons. J. $\mathrm{CO}_{2}$ Util. 2021, 44, 101413. [CrossRef]

9. Da Cruz, T.T.; Balestieri, J.A.P.; de Silva, J.M.T.; Vilanova, M.R.; Oliveira, O.J.; Ávila, I. Life cycle assessment of carbon capture and storage/utilization: From current state to future research directions and opportunities. Int. J. Greenh. Gas Control 2021, 108, 103309. [CrossRef]

10. Saravanan, A.; Kumar, P.S.; Vo, D.V.N.; Jeevanantham, S.; Bhuvaneswari, V.; Anantha Narayanan, V.; Yaashikaa, P.R.; Swetha, S.; Reshma, B. A Comprehensive Review on Different Approaches for $\mathrm{CO}_{2}$ Utilization and Conversion Pathways. Chem. Eng. Sci. 2021, 236, 116515. [CrossRef]

11. Yu, D.-G.; He, L.-N. Introduction to $\mathrm{CO}_{2}$ utilisation. Green Chem. 2021, 23, 3499-3501. [CrossRef]

12. Gennaro, A.; Isse, A.A.; Savéant, J.M.; Severin, M.G.; Vianello, E. Homogeneous Electron Transfer Catalysis of the Electro-chemical Reduction of Carbon Dioxide. Do Aromatic Anion Radicals React in an Outer-Sphere Manner? J. Am. Chem. Soc. 1996, 118, 7190-7196. [CrossRef]

13. Mena, S.; Guirado, G. Electrochemical Tuning of $\mathrm{CO}_{2}$ Reactivity in Ionic Liquids Using Different Cathodes: From Oxalate to Carboxylation Products. C 2020, 6, 34. [CrossRef] 
14. Matthessen, R.; Fransaer, J.; Binnemans, K.; De Vos, D.E. Electrocarboxylation: Towards sustainable and efficient synthesis of valuable carboxylic acids. Beilstein J. Org. Chem. 2014, 10, 2484-2500. [CrossRef] [PubMed]

15. Senboku, H.; Katayama, A. Electrochemical carboxylation with carbon dioxide. Curr. Opin. Green Sustain. Chem. 2017, 3, 50-54. [CrossRef]

16. Isse, A.A.; Ferlin, M.G.; Gennaro, A. Homogeneous electron transfer catalysis in the electrochemical carboxylation of arylethyl chlorides. J. Electroanal. Chem. 2003, 541, 93-101. [CrossRef]

17. Isse, A.A.; Falciola, L.; Mussini, P.R.; Gennaro, A. Relevance of electron transfer mechanism in electrocatalysis: The reduction of organic halides at silver electrodes. Chem. Commun. 2005, 1, 344-346. [CrossRef]

18. Isse, A.A.; Durante, C.; Gennaro, A. One-pot synthesis of benzoic acid by electrocatalytic reduction of bromobenzene in the presence of $\mathrm{CO}_{2}$. Electrochem. Commun. 2011, 13, 810-813. [CrossRef]

19. Reche, I.; Mena, S.; Gallardo, I.; Guirado, G. Electrocarboxylation of halobenzonitriles: An environmentally friendly synthesis of phthalate derivatives. Electrochim. Acta 2019, 320, 134576. [CrossRef]

20. Isse, A.A.; Galia, A.; Belfiore, C.; Silvestri, G.; Gennaro, A. Electrochemical reduction and carboxylation of halobenzophenones. J. Electroanal. Chem. 2002, 526, 41-52. [CrossRef]

21. Mena, S.; Loault, C.; Mesa, V.; Gallardo, I.; Guirado, G. Electrochemical reduction of 4-nitrobenzyl phenyl thioether for activation and capture of $\mathrm{CO}_{2}$. ChemElectroChem 2021, 21, 1-14.

22. Tan, X.; Sun, X.; Han, B. Ionic Liquid-Based electrolytes for $\mathrm{CO}_{2}$ electroreduction and $\mathrm{CO}_{2}$ electroorganic transformation. Natl. Sci. Rev. 2021, 1-41. [CrossRef]

23. Mena, S.; Gallardo, I.; Guirado, G. Electrocatalytic Processes for the Valorization of $\mathrm{CO}_{2}$ : Synthesis of Cyanobenzoic Acid Using Eco-Friendly Strategies. Catalysts 2019, 9, 413. [CrossRef]

24. Mena, S.; Sanchez, J.; Guirado, G. Electrocarboxylation of 1-chloro-(4-isobutylphenyl)ethane with a silver cathode in ionic liquids: An environmentally benign and efficient way to synthesize Ibuprofen. RSC Adv. 2019, 9, 15115-15123. [CrossRef]

25. Mena, S.; Santiago, S.; Gallardo, I.; Guirado, G. Sustainable and efficient electrosynthesis of naproxen using carbon dioxide and ionic liquids. Chemosphere 2020, 245, 125557. [CrossRef] [PubMed]

26. Ma, J.-A.; Cahard, D. Strategies for nucleophilic, electrophilic, and radical trifluoromethylations. J. Fluor. Chem. 2007, 128, 975-996. [CrossRef]

27. Yoo, W.J.; Kondo, J.; Rodríguez-Santamaría, J.A.; Nguyen, T.V.Q.; Kobayashi, S. Efficient Synthesis of $\alpha$-Trifluoromethyl Carboxylic Acids and Esters through Fluorocarboxylation of Gem-Difluoroalkenes. Angew. Chem. Int. Ed. 2019, 58, 6772-6775. [CrossRef] [PubMed]

28. Andrieux, C.P.; Combellas, C.; Kanoufi, F.; Savéant, J.M.; Thiébault, A. Dynamics of Bond Breaking in Ion Radicals. Mech-anisms and Reactivity in the Reductive Cleavage of Carbon-Fluorine Bonds of Fluoromethylarenes. J. Am. Chem. Soc. 1997, 119, 9527-9540. [CrossRef]

29. Isse, A.A.; Gottardello, S.; Durante, C.; Gennaro, A. Dissociative electron transfer to organic chlorides: Electrocatalysis at metal cathodes. Phys. Chem. Chem. Phys. 2008, 10, 2409-2416. [CrossRef]

30. Reche, I.; Gallardo, I.; Guirado, G. Cyclic voltammetry using silver as cathode material: A simple method for determining electro and chemical features and solubility values of $\mathrm{CO}_{2}$ in ionic liquids. Phys. Chem. Chem. Phys. 2015, 17, 2339-2343. [CrossRef] 